\title{
Importance of Environment Protection on the Global Level
}

\author{
Sinisa Franjic* \\ Bosnia and Herzegovina, Europe
}

*Corresponding author: Sinisa Franjic, Faculty of Law, Bosnia and Herzegovina, Europe.

\author{
Received Date: December 03, 2018 \\ Published Date: December 17, 2018
}

\begin{abstract}
Environmental protection is one of the basic prerequisites for the overall development of any country in the world. If economic growth and development are to be established, and there is no country in the world that does not want to do so, biodiversity must be contributed. As awareness of environmental protection is developed, human awareness is also developed about the need to preserve the environment by preventing adverse impacts on nature. Law, as a scientific discipline, plays a significant role in these endeavors.
\end{abstract}

Keywords: Environment; Protection; Health; Law

\section{Introduction}

For millennia, nature-specifically living systems-provided food and fiber to nourish and clothe us and materials to build us homes and transport [1]. Living systems conditioned the air we breathe, regulated the global water cycle, and created the soil that sustained our developing agriculture. They decomposed and absorbed our wastes. Beyond practicality, nature fed the human spirit. But pressure on nature from the impact of 6 billion humans is taking its toll. Living systems worldwide are collapsing. Changes in Earth's biota caused by human actions range from indirect depletion caused by altering Earth's physical and chemical environment to direct depletion of human and nonhuman life. We have not always had such devastating effects. When modern humans emerged some 200,000 years ago, changes we caused happened slowly, and over relatively small geographic scales. But now change is fast, fueled by unconstrained population growth and advancing technologies. "Humandominated ecosystems" are not simply fa rm fields but the entire planet. The ecological footprint of modern human society is huge. The result is global ecological disruption and biotic impove rishment. Yet modern society continues to behave as if there were no long-term consequences of transforming the biosphere, as if we were not connected to nature's life-support systems.

For thousands of years, people worried most about the health of individuals, including injuries in fights or wars, periodic famine, vector-borne diseases, and accidents. Modern agriculture and the domestication of animals created new health challenges by transferring a vast array of new contagious diseases to humans. The industrial revolution brought some relief; wastewater treatment, for example, reduced the incidence of waterborne diseases. But new technologies generated new threats, ranging from toxic industrial chemicals to global transportation systems that spread infectious diseases and exposed individuals to a greater variety of diseases. Modern environmental regulation and medicine have attacked these problems, but they struggle to stay ahead of evolving, unforeseen consequences, such as the resistance of many disease organisms to antibiotics. The human condition has, of course, been the subject of intellectual and practical concern since civilization began. But economic and political changes during the industrial revolution moved humans away from their ties to the land. Technology and trade liberated people from concerns about life-support systems, or so it seemed. Lessons of the past--especially accumulated knowledge about connections to living systems-seemed increasingly irrelevant. Emerging economic theories suggested that "the market" would, if allowed to operate freely, provide for humankind. So-called neoclassical economics argued (incorrectly) that economic growth and the forces that promote it are good for the environment and for the poor. The attainment of societal well-being was assumed to be an inevitable by-product of a market economy. Present environmental trends and the growing gap between rich and poor demonstrate that this assumption is flawed. 
We are increasingly conscious of the effects of our activities on the natural environment [2]. Man has always affected the environment to some extent, but this has become a serious matter of public concern during the last century. These effects may be classified according to the area used or affected by the energy generators, and by the pollution they produce. This pollution may be local or global, and includes not only poisonous chemicals, but also visual and aural pollution, and affects the atmosphere, the land and the sea. When considering man-made pollution, it is useful in appropriate cases to put it in perspective by comparing it with the natural sources of pollution that are beyond our control. Thus, bush fires due to lightning strikes have always occurred, and are even necessary for the germination of some plants. Volcanic eruptions throw huge amounts of poisonous chemicals into the atmosphere, and this falls on land and sea. The earth has great natural recuperative powers and, once the source of the pollution is removed, the land, lakes and seas return to their previous state. Reflect for a moment on the miracle - the extraordinarily rare combination of factors that together makes life on earth possible [3]. Our planet's ideal position in the right kind of galaxy, the right distance from a perfect star, the right tilt for seasons, exactly enough of a protective stratospheric radiation shield, a thin layer of breathable atmosphere, Sample water resources, a moderate temperature range, sunlight, moderate terrain, energy and minerals, photosynthesis, the hydrologic cycle, the carbon cycle, living soils, flora, and fauna. Contemplate its magnificence - from outer space, the "piercingly beautiful" blue globe our astronauts see hanging in the void, or from a down-toearth panorama of its incredible landforms, mountains, canyons, plains, oceans, sea beds, rivers, lakes, wetlands, forests, jungles, archipelagos, deserts, fjords, glaciers, and ice fields. Then think of the incredibly rich life forms, species, and ecosystems that exist at this brief point in the billions of years the earth has been evolving.

\section{Ecology}

Ecology aims to understand how natural systems such as plant and animal communities are organized and function [4]. This includes investigating the subsystems and other parts of natural systems, the relationships among them, and the processes at and above the level of the individual organism that allow biological systems to persist and evolve as dynamic entities. Modern ecology emerged from the study of natural history, which focused primarily on compiling descriptions and catalogues of plants and animals and which generally considered biological systems (including species) to be static entities. After Charles Darwin' s On the Origin of Species was published in 1859, the fact that living organisms undergo change through the process of natural selection began to be incorporated into ecological study of the dynamics of natural systems. Thus, ecology and evolutionary biology are closely allied and are considered one field by many biologists. Although ecology developed during the nineteenth and twentieth centuries as a natural science, many of its concepts and principles have been applied to other fields, ranging from human social development to social and cultural systems and to epidemiology. Also, the traditional focus on the study of natural systems such as forests, grasslands, wetlands, rivers, lakes, and oceans has increasingly been extended beyond purely natural systems. For example, the application of ecological thinking began expanding by the mid-twentieth century to encompass human-built and "hybrid" human-natural systems such as cities and cultivated landscapes. Recently, a social-ecological systems perspective and resilience theory have developed within the field of ecology to deal explicitly with humans and nature as a single, integrated, and complex system. This integrative approach to understanding living systems has been found necessary to meaningfully address issues such as sustainability, a concept that implies the dependence of human health and well-being on healthy ecosystems. In this way ecology has become as much a worldview as a scientific discipline.

\section{Environmental Legacy Act}

A baseline is a point of departure; a benchmark; a point along a continuum that marks progress toward a goal [5]. Central to the design of the National Environmental Legacy Act (Legacy Act or Act) is the collection of baseline data about natural resources, the definition of the nature and quality of the environmental legacy to be preserved, and ongoing monitoring to ensure preservation of the desired legacy. If the goal of the Legacy Act's to ensure the intergenerational transfer of a legacy, then a baseline must be set, benchmarks for success established, and current ecological realities confronted. None of these are simple tasks, and they have been made infinitely more complicated by the accelerated pace of anthropogenic change, which has resulted in both shifting and already-shifted baselines. We use the term "shifting baselines" to describe the phenomenon of how humans' perception of normal or baseline environmental conditions can shift dramatically over time, particularly between generations. The pitfall of shifting baselines is that environmental degradation often goes unrecognized by successive generations, which may not appreciate the degraded state of what they perceive as a pristine and functional ecosystem.

The shifting-baselines phenomenon poses several major challenges to designing an effective Legacy Act. First, if we fail to consider historical environmental conditions and set conservation goals based on already-shifted baselines, we may constrain - even doom - the resource legacy we seek to transfer. Second, resource management decisions that fail to address gradual environmental change may subtly shift baselines, diminish the environmental legacy, and eventually push ecosystems to the brink. Finally, accelerated anthropogenic change ensures that some baselines will shift irreversibly, and in some cases, new, transformed ecosystems will emerge and stabilize within foreseeable generations. Failure to understand and address these challenges in ways more sophisticated than the traditional metrics of species counts, acreage amounts, and pollutant levels could doom Legacy Act. To preserve the options available to future generations, an effective legacy act must consider the legacy of ecological functions, processes, services, and their interactions, as well as the ability of ecosystems to absorb and adapt to change.

\section{Environmental Law}

Over the past four decades, environmental law has evolved into a legal system of statutes, regulations, guidelines, requirements, policies, and case-specificjudicial and administrative interpretations 
that address a wide-ranging set of environmental issues and concerns [6]. These laws and requirements address not only the natural environment, including the air, water, and land, but also how humans interact with that natural environment and ecological systems. In addition, this system of environmental laws involves multiple layers of regulatory controls, since not only the federal government, but also state and local levels of government, have imposed interrelated and sometimes overlapping environmental requirements. This legal system is complex in itself and is made even more challenging by the difficulty of the interdisciplinary subject matter to be regulated (health, safety, and environment) and the quickly evolving scientific and technical issues typically presented in environmental cases. Environmental laws and policies are predominantly goal-oriented [7]. Standards, principles and procedures for the protection of the environment are often instrumental to achieve, say, the conservation of fragile ecosystems and endangered species, the preservation of fresh water and other natural resources, the restoration of contaminated soils as well as the stratospheric ozone layer, and the protection of human health. This goal oriented feature is evident in national as well as international law. It is apparent also when legal approaches to managing environmental problems are compared with economic or market-based instruments, such as emission trading, environmental taxes and voluntary agreements and codes of conduct. National statutes and international treaties, standards, instruments and procedures are assessed with these underlying objectives in mind, and mainly analyzed in terms of effectiveness and achievability of the set objectives. Even sustainable development, as an overarching societal objective with obvious environmental connotations, reflects this goal-oriented conception of environmental law and policy.

Yet, environmental law also involves priorities, conflicts and clashes of interests - and concerns for justice and fairness. In fact, any drafting, negotiation, adoption, application and enforcement of environmental laws-indeed comprehending environmental law in general-induces justice considerations, i. e. concerns for the distributive and corrective effects of laws and decisions pertaining to health, the environment and natural resources, as well as concerns for the opportunities of those potentially affected to participate in such law-making and decision-making in the first place. Although well established concepts in environmental law, whether based on custom or statutes, appear neutral on their face, a closer study, or simply placing them in a context, may reveal disproportionate burdening or restricting effects for certain groups or categories when these concepts are applied. It may also show how certain interests or subjects are ignored or demeaned. Such concerns are indeed raised in local as well as global contexts, and they also include structural issues, such as gender, class, ethnicity and - on a global scale - North-South relations.

\section{International Environmental Law}

International environmental law is notoriously uncertain in relation to the normative content of its norms [8]. There are many factors which contribute to this state of affairs, one of them, for example, being the method of international law making, which in many cases is based on the principle of the balancing of the interests of all interested parties, such as the management and apportionment of rights in relation to international watercourses and the responsibility of States for environmental damage, which relies to a certain degree on this principle. Other factors, which play a significant role in environmental norm-setting, are the competing interests and differentiation in the legal position of developed and developing States, i.e. the competing interests and differentiation are reflected in the principle of common but differentiated responsibilities.

Policy makers responding to these demands increasingly understand that environmental protection must be addressed in a holistic and expansive manner [9]. Local problems cannot be separated from national, regional, or even global conditions. As a result, the interface of domestic (both national and local) and international environmental law has rapidly expanded. Such an evolution corresponds to the physical reality of a biosphere composed of interdependent elements that do not recognize political boundaries and the increasingly transnational character of the human activities that harm nature and its processes. Internationalization of markets and the emergence of a global civil society present new opportunities as well as new challenges. Communication networks make possible more rapid knowledge of the existence and scope of environmental problems, but the widespread movement of persons and products may also contribute to those problems, for example, through the introduction of alien's pieces and the spread of pollutants. Overconsumption threatens to exhaust living and nonliving resources, whereas rising greenhouse gas emissions detrimentally modify the global climate. Population concentrations strain resources and create levels of pollution beyond the earth's assimilative capacity. New problems resulting from technology and changes in the nature or scope of human activities are constantly being identified, such as the introduction of unprocessed endocrine-disrupting pharmaceuticals into fresh water. As a consequence, there is a constant need to develop and revise the national and international legal framework. The geographic scope of environmental law is global, but so are its interdisciplinary requirements. Beyond such obvious topics as water law and endangered species legislation, laws and policies concerning energy, trade, investment, transportation, and consumer protection also affect environmental conditions. At the center of the problems, impacts, and solutions are individuals with rights guaranteed by national and international law.

\section{Economic Analysis of Environmental Protection}

The relevance of economics for the evaluation and design of environmental policy has numerous dimensions [10]. Some relate to the basis for environmental decision making, e.g., the use of cost-benefit analysis to determine whether and to what extent to regulate, while others are instrumental, e.g., the use of market-based instruments to achieve environmental goals. First, environmental resources, amenities, and quality have economic value. Second, while markets are useful in providing society with goods and services in general, there are serious market imperfections (what some describe as market failures) that justify government 
intervention to protect the environment. Third, in the proper context, economics can contribute to evaluating and prioritizing alternative policies for improving the environment, both within a given area of concern (such as the reduction of air pollution from a variety of sources) and among different areas of concern (such as air pollution, water pollution, and hazardous wastes). Fourth, economics, through the application of cost-benefit analysis, offers an alternative policy rationale for determining whether, and to what extent, a environmental problem should be controlled or addressed. Finally, market-based instruments are increasingly promoted as complements to, and sometimes as substitutes for, traditional regulatory approaches.

In general, the trend toward market-based decision making and control represents a shift away from some of the values underlying the congressional mandates embodied in many of the nation's bedrock environmental statutes. This is illustrative of the fact that economics and law compete politically for dominance in environmental policy formulation. In contemporary environmental law and policy, economic analysis provides the dominant theoretical framework for thinking and reasoning about environmental protection [11]. Broadly speaking, this framework involves evaluating environmental protection with respect to the goal of producing economically efficient policies and valuing specific environmental resources with respect to their success in satisfying the subjective preferences that people express as consumers making market choices. Various laws and executive orders require this kind of analysis, and advocates of both weaker and stronger environmental protection often draw on such analyses to influence the public debate in ways that support their favored view of policy decisions. While economic analysis is not the only type of assessment that policy practitioners employ, the significant legal and political influence of economic analysis in the area of environmental protection inspires much of this book's effort to advance a different framework for evaluating and justifying environmental protection. The normative criterion that grounds the framework that this book advances is social justice. The idea that public policy should be guided by concerns of social justice rather than economic efficiency arises in various forms of legal and political reasoning about the distributional impacts of environmental protection. A law setting national standards for air quality, for example, will require polluting industries to invest a certain amount of money in pollution control, and it will benefit citizens that would otherwise breathe polluted air. But the impact of pollution control is much more complicated than this, for there will be significant variation in the air quality the beneficiaries experience. For instance, enforcement of environmental protection laws will vary depending on the racial composition of communities in which environmental laws have been violated. Likewise, a given pollution control standard will be violated more often in certain geographical locations. A given standard will also provide fewer absolute benefits to people who cannot or do not avoid the worst exposures, such as people who work or exercise outdoors. If exposure to air pollution results in medical disorders, such as asthma or other respiratory illnesses, then people who cannot afford medical treatment will get fewer overall benefits from an established level of air quality.

\section{Liability in International Environmental Law}

Liability and state responsibility rules determine whether the polluter pays principle is a principle of consequence in international environmental law or if it is just a principle that hardly applies in practice [12]. Most international liability regimes channel liability to the person who is in control of an environmentally damaging activity. In the case of oil pollution and the sea transfer of hazardous substances, the person in control is the shipowner. In the case of nuclear pollution, it is the operator of a nuclear power plant. In the case of carriage of dangerous goods, it is the carrier of dangerous goods. In the case of waste exports, the person who gives notification to the country of destination that a waste transfer is to take place is the person who is liable until the disposer takes control of the waste. From that point on, the disposer is considered liable. The channeling of liability to the person in control of a dangerous activity is necessary in order to reduce the transaction costs of finding the responsible person. A presumption, therefore, is made that the person in control of the activity should be the liable person. Liability is strict because a fault liability regime would have created further costs of finding whether the person in control was actually at fault. A further presumption, thus, is made that most activities, especially those that involve ultrahazardous substances, are likely to create some environmental externalities no matter the amount of precaution taken. The person in control of the activity should bear the costs of these externalities.

A broad definition of the polluter pays principle, to implicate a society that benefits from dangerous activities, is at odds with an understanding of the historical origins of the principle. The purpose of the polluter pays principle, as initially envisioned, is to make industries absorb the negative externalities they create. If one views not industry but society, in general, as the beneficiary from dangerous activities, then the responsibility for the occurrence of environmental accidents should shift to the society at large. The international system, at this point, attempts to forge a balance between a strict sense version of the polluter pays principle and a broader version that takes into account collective choices that societies make to undertake dangerous activities and, thus, the benefits and costs emanating from such activities. Furthermore, for a strict sense version of the polluter pays principle to work, industry must not be able to pass on the costs that come from its activities to consumers. The ability of the industry to pass on the costs to consumers depends on the elasticity of demand and options available to consumers to switch to less dangerous substitutes. If such substitutes are not available or are available but not as affordable as the products they are to replace, then the polluter pays principle is unlikely to affect the competitiveness of a polluting industry.

\section{Environmental Health}

A healthy environment promotes healthful conditions necessary to sustain living creatures [13]. While this observation seems obvious, in practice, societies that have developed vigorous agricultural and industrial bases have found that pollution became a consequence of those activities. Air quality deteriorated, water purity diminished, and lands became fouled by chemical and 
other hazardous substances. As biomedical research on the effects of environmental hazards progressed, it became evident that environmental degradation was associated with adverse effects on the health of human populations and ecosystems. From the perspectives of affected communities, the harms of environmental contamination are many and interrelated [14]. These harms include adverse impacts to ecological health and to humans' physical, psychological, social, cultural, and spiritual health. In many instances, these harms represent an affront not only to an individual, but also to a group. When health and environmental agencies evaluate and respond to the harms of environmental contamination, however, they frequently consider the problem in terms of risk to human health-understood in the narrow, individual physiological sense of the term. Agencies for the most part proceed chemical by chemical and consider whether human contact with that chemical is expected to result in an increased likelihood of various human health "endpoints" such as neurological damage or cancer. Agencies make this determination by means of risk assessment, an analytical tool that produces a quantitative prediction of this increase for given levels of environmental contamination. Physicians are increasingly called upon to address questions related to environmental health [15]. Pollution of air and water, contamination of food, releases from industrial facilities or waste sites, and hazards in the home are all common causes for concern among patients, community members, the media, and public officials. All health care providers should understand how to approach clinical and public health problems in environmental health, as well as the similarities and differences between occupational health and environmental health.

Although environmental issues are important worldwide, the severity and nature of the problem differs geographically, with especially serious hazards in newly industrializing countries. Many developed countries have taken significant steps in recent decades to address pervasive problems such as air pollution and contamination of drinking water. These countries continue to face issues around the safety of chemicals in consumer products, legacy contamination from historic industrial uses, and emerging concerns about recently identified chemical hazards. Developing countries, in contrast, have faced enormous increases in industrial pollution. The dramatic expansion in motor vehicles worldwide, the shift of industrial production to nations where environmental laws are less stringent and their enforcement is often nonexistent, and the practice of shipping hazardous waste to less-developed countries for recycling or storage, have all created massive and relatively new environmental problems around the globe. In particular, air pollution and contamination of the water and food supply are very serious concerns in the developing world. Meanwhile global threats such as climate change, depletion of natural resources, and the pervasive presence of persistent bioaccumulative chemicals in the environment threaten health throughout the world.

\section{Conclusion}

The law to environmental protection includes all legal norms related to environmental protection, with the aim of preventing adverse impacts on nature. The defense power of nature is becoming weaker, and awareness of the necessity of protecting natural resources is becoming more and more neglected. These are the main reasons why legal regulation in this area is a necessity at national and international level. The issue of environmental pollution today is a global problem that needs to be addressed in the international context.

\section{Acknowledgement}

None.

\section{Conflict of Interest}

No Conflict of Interest.

\section{References}

1. Karr JR (2000) Health, Integrity, and Biological Assessment: The Importance of Measuring Whole Things. In: Pimentel D, Westra L, Noss RF (Eds.) Ecological Integrity - Integrating Environment, Conservation, and Health, Island Press, Washington, pp. 209 - 210.

2. Hodgson PE (2010) Energy, the Environment and Climate Change, Imperial College Press, London, pp. 87.

3. Nanda VP, Pring G (2013) International Environmental Law and Policy for the $21^{\text {st }}$ Century, 2nd Revised Edition, Martinus Nijhoff Publishers, Leiden, pp. 3.

4. Wilcox B, Jessop H. (2010): Ecology and Environmental Health in Frumkin H (Ed) Environmental Health - From Global to Local, Second Edition, Jossey-Bass, John Wiley \& Sons, Inc., Hoboken, pp. 6.

5. Ankersen TT, Regan KE (2010) Shifting Baselines and Backsliding Benchmarks - The Need for the National Environmental Legacy Act to Address the Ecologies of Restoration, Resilience, and Reconciliation in Flournoy AC, Driesen DM (Eds.) Beyond Environmental Law - Policy Proposals for a Better Environmental Future, Cambridge University Press, Cambridge, pp. $53-54$.

6. Steinway DM (2014) Fundamentals of Environmental Law in Sullivan TFP (ed) Environmental Law Handbook, Twenty-second Edition, Bernan Press, Lanham, pp. 1.

7. Ebbesson J (2009) Introduction dimensions of justice in environmental law in Ebbesson J, Okowa Ph. (Eds.) Environmental Law and Justice in Context Cambridge University Press, Cambridge, pp. 1.

8. Fitzmaurice M (2009) Contemporary Issues in International Environmental Law, Edward Elgar Publishing Limited, Cheltenham, pp. 6.

9. Anton DK, Shelton DL (2011) Environmental Protection and Human Rights, Cambridge University Press, Cambridge, pp. 1.

10. Ashford NA, Caldart CC (2008) Environmental Law, Policy, and Economics - Reclaiming the Environmental Agenda, Massachusetts Institute of Technology, Cambridge, pp. 128.

11. Holland B (2014) Allocating the Earth - A Distributional Framework for Protecting Capabilities in Environmental Law and Policy, Oxford University Press, Oxford, pp. 1. -2.

12. Louka E (2006) International Environmental Law - Fairness, Effectiveness, and World Order, Cambridge University Press, Cambridge, pp. 448. -449 .

13. Johnson BL, Lichtveld MY (2018) Environmental Policy and Public Health, Second Edition, CRC Press, Taylor \& Francis Group, pp. 3.

14. Rechtschaffen C, Gauna E, O’Neill CA (2009) Environmental Justice - Law, Policy \& Regulation, Second Edition, Carolina Academic Press, Durham, pp. 175.

15. Solomon GM (2014) Principles of Environmental Health in La Dou J, Harrison RJ (Eds...) CURRENT Occupational and Environmental Medicine, Fifth Edition, McGraw-Hill Education, New York, pp. 1608. 